\title{
Effect of cobalt enrichment on growth and hydrocarbon accumulation of Botryococcus braunii with immobilized biofilm attached cultivation
}

\author{
Pengfei Cheng ${ }^{\mathrm{a}, \mathrm{b}}$, Junfeng Wang ${ }^{\mathrm{a}, *}$, Tianzhong Liu ${ }^{\mathrm{a}}$ \\ ${ }^{a}$ Key Laboratory of Biofuels, Qingdao Institute of Bioenergy and Bioprocess Technology, Chinese Academy of Sciences, Qingdao, Shandong 266101, PR China \\ ${ }^{\mathrm{b}}$ University of Chinese Academy of Sciences, Beijing 100049, PR China
}

\section{H I G H L I G H T S}

- Botryococcus survived high cobalt concentration of $4.5 \mathrm{mg} \mathrm{L}^{-1}$.

- Hydrocarbon and its long chain component were increased under cobalt enrichment.

- Attached cultivation of B. braunii might be high efficient in cobalt removal.

\section{A R T I C L E I N F O}

\section{Article history:}

Received 29 September 2014

Received in revised form 21 November 2014

Accepted 22 November 2014

Available online 27 November 2014

\section{Keywords:}

Botryococcus brauni

Cobalt enrichment

Attached cultivation

Hydrocarbon

\begin{abstract}
A B S T R A C T
The effects of cobalt enrichment on the growth and hydrocarbon accumulation were studied with biofilm attached cultivation. Under biofilm attached cultivation conditions, the microalga Botryococcus braunii survived high concentration of cobalt $(50 \times$ normal level). The crude hydrocarbon content as well as the long $\mathrm{C}$ chain component (C31) increased under Co enrichment treatment indicating the activity of key enzyme that catalyze hydrocarbon synthesis might be enhanced by Co enrichment. The reduced carbohydrate and protein contents accompanied by increased hydrocarbon content for Co enrichment treatment indicating the Co was also an effective factor that controls the carbon flow of $B$. braunii. Under Co enrichment treatment, totally $1473.9 \mu \mathrm{mol}$ of Co element was consumed to produce one gram of algal biomass, indicating this attached cultivation method is high efficient in heavy metal elements removal.
\end{abstract}

(c) 2014 Elsevier Ltd. All rights reserved.

\section{Introduction}

Botryococcus braunii is a colonial green microalga that can produce extracellular hydrocarbons at a high rate (Banerjee et al., 2002; Weiss et al., 2010; Metzger and Largeau, 2005), and because of this, it is considered as one of the most promising feedstock for sustainable biofuel production. Meanwhile, B. braunii is also a "famous" algal species for its slow growth rate as well as difficult in scaling up (Ruangsomboon, 2012; Baba et al., 2012). Recently, we introduced a novel cultivation system based on biofilm technology, which is called "attached cultivation" (Liu et al., 2013). Results have proved that this "attached cultivation" system is high efficient in biomass production for many oleaginous microalgae, including B. braunii (Cheng et al., 2013, 2014). Besides this increased photosynthetic efficiency, one of the most attractive merits for this biofilm method is the huge water saving potential

\footnotetext{
* Corresponding author. Tel./fax: +86 53280662735.

E-mail address: wangjf@qibebt.ac.cn (J. Wang).
}

due to the separation of aqua-medium with the algal biomass (Ji et al., 2014).

For conventional aqua-suspended cultivation system (mainly open pond and varieties of closed photobioreactors), the nutrient starvation, especially nitrogen starvation is the dominating method to induce the accumulation of secondary metabolisms, meanwhile, the enrichment of specific nutrient component was seldom applied. It is surely a rational choice when considering the huge amount of salt it required to keep a proper concentration in big water body, especially some of the salt is not environmental friendly. However, if the water volume involved in cultivation was greatly reduced, as it in the biofilm attached cultivation, this inducing strategy of nutrient enrichment deserves a re-consideration because many studies indicated that some elements serve critical physiological functions and the enrichment of them will benefit the algal cells. For example, Rousch and Sommerfeld (1999) found that $\mathrm{Mn}^{2+}$ was indispensable and was the catalyst of photosynthesis and the activator of some kind of enzymes in microalgae. Boyer and Brand (1998) reported that suitable concentration of $\mathrm{Zn}^{2+}$, $\mathrm{Mn}^{2+}$, and $\mathrm{Fe}^{3+}$ could cause the biomass increase of microalgae. 
In this research, the effects of cobalt (Co) enrichment on growth and hydrocarbon accumulation were investigated with biofilm attached cultivation. We focused on the trace element of Co because a Co-porphyrin containing enzyme that located in the microsomes, catalyzes decarbonylation of aldehydes which is the final step in hydrocarbon biosynthesis (Dennis and Kolattukudy, 1992), and this Co-containing enzyme seemed to be a specific enzyme that only found in Botryococcus (Dennis and Kolattukudy, 1992; Koboyashi and Shimizu, 1999). We hypothesized that the hydrocarbon content as well as the long chain component will increase under high Co treatment because of the enhanced content and/or enzyme activity.

\section{Methods}

\subsection{Algal strain and inocula preparation}

The microalgae strain $B$. braunii SAG 807-1 (A race) was purchased from SAG culture collection, University of Göttingen, Germany. In order to prepare the inocula for attached bioreactors, the alga was firstly cultivated in glass bubbling columns (diameter $=0.05 \mathrm{~m}$ ) until the exponential growth phase had been reached (ca. 2 weeks). The glass columns contained $0.7 \mathrm{~L}$ of algal broth and were continuously illuminated by cold-white fluorescent lamps (NFL28-T5, NVC, China) with light intensity of $60 \mu \mathrm{mol} \mathrm{m}^{-2} \mathrm{~s}^{-1}$. The broth temperature was $25 \pm 2{ }^{\circ} \mathrm{C} . \mathrm{CO}_{2}$ enriched air $(1 \% \mathrm{v} / \mathrm{v})$ was continuously injected into the bottom of the columns with a speed of $1 \mathrm{vvm}(0.7 \mathrm{~L} / \mathrm{min}$ for each column) to agitate the algal broth as well as supply carbon.

\subsection{Culture medium}

In this research, inocula culture of $B$. braunii were maintained on Chu 13 medium, each liter of which contains: $200 \mathrm{mg} \mathrm{KNO}_{3}$, $52 \mathrm{mg} \mathrm{K} \mathrm{HPO}_{4} \cdot 3 \mathrm{H}_{2} \mathrm{O}, 100 \mathrm{mg} \mathrm{MgSO}_{4} \cdot 7 \mathrm{H}_{2} \mathrm{O}, 40.7 \mathrm{mg} \mathrm{CaCl}, 10 \mathrm{mg}$ NaFeEDTA, $2.86 \mathrm{mg} \mathrm{H}_{3} \mathrm{BO}_{3}, 1.54 \mathrm{mg} \mathrm{MnSO}_{4} \cdot \mathrm{H}_{2} \mathrm{O}, 0.22 \mathrm{mg} \mathrm{ZnSO}$ $.7 \mathrm{H}_{2} \mathrm{O}, \quad 0.09 \mathrm{mg} \quad \mathrm{CoSO}_{4} \cdot 7 \mathrm{H}_{2} \mathrm{O}, \quad 0.08 \mathrm{mg} \quad \mathrm{CuSO}_{4} \cdot 5 \mathrm{H}_{2} \mathrm{O}, \quad 0.06 \mathrm{mg}$ $\mathrm{Na}_{2} \mathrm{MoO}_{4} \cdot 2 \mathrm{H}_{2} \mathrm{O}$ (Largeau et al., 1980). For the Co enrichment treatments, the modified Chu 13 with different Co concentrations were involved, viz. 0.09, 0.18, 0.45, 0.90, 4.5 and $45 \mathrm{mg} \mathrm{L}^{-1}$, corresponding to $1 \times, 2 \times, 5 \times, 10 \times, 50 \times$ and $500 \times$ of original Co concentration.

\subsection{Photobioreactor}

The biofilm attached cultivation system applied in this research was similar to that of the type 1 reactor in Liu et al. (2013) and as descripted in detail in Cheng et al. (2014). In brief, a glass chamber including a glass plate and attached algal biofilm disks were placed on an iron rack with a certain tilt angle against the horizontal plane. The medium was propelled $\left(1.2 \mathrm{~L}\right.$ in total, ca. $\left.10 \mathrm{ml} \mathrm{min}^{-1}\right)$ by a peristaltic pump (TP12DC $12 \mathrm{~V}$, Guangzhou JU PlasFitting Technology Co., LTD, China) to circulate inside the system. The light intensity measured inside the chamber at the position of attached algal cells was $100 \pm 10 \mu \mathrm{mol} \mathrm{m}{ }^{-2} \mathrm{~s}^{-1}$ with cold-white fluorescent lamps. Continuous airflow containing $1 \% \mathrm{CO}_{2}(\mathrm{v} / \mathrm{v})$ was injected into the glass chamber with a speed of $0.1 \mathrm{vvm}$ to supply carbon source and the temperature inside the glass chamber was $25 \pm 2{ }^{\circ} \mathrm{C}$ during the experiments. Each period of culture was maintained of 8 days for all the attached cultivation.

\subsection{Experiment design}

The effects of cobalt on growth and hydrocarbon, carbohydrate and protein production of $B$. braunii were studied. The rinsed algal cells with modified Chu 13 media contain 0.09, 0.18, 0.45, 0.90,
4.50 and $45.00 \mathrm{mg} \mathrm{L}^{-1}$ cobalt were cultivated with circulated attached photobioreactor. The effect of cobalt concentration of $4.50 \mathrm{mg} \mathrm{L}^{-1}$ (cobalt enrichment) on hydrocarbon, carbohydrate and protein production was further investigated.

\subsection{Biomass estimation}

The biomass concentration of an 'algal disk' $\left(D W, \mathrm{gm}^{-2}\right)$ was determined with gravimetric method (Liu et al., 2013). Cells coming from the 'algal disk' were rinsed and re-suspended with de-ionized water and then filtered to pre-weighted $0.45 \mu \mathrm{m} \mathrm{GF} / \mathrm{C}$ filter membrane (Whatman, England; $D W_{0}$ ). The membrane was oven dried at $105^{\circ} \mathrm{C}$ for $12 \mathrm{~h}$ and then cooled down to room temperature to measure dry weight $\left(D W_{1}\right)$. The $D W$ was calculated as follows:

$D W=\left(D W_{1}-D W_{0}\right) / 0.001$

where the 0.001 represented the footprint area of 'algal disk' $\left(\mathrm{m}^{2}\right)$.

\subsection{Hydrocarbon extraction and analysis}

The extraction of hydrocarbon was determined according to Sawayama et al. (1992) and Cheng et al. (2013). Some $50 \mathrm{mg}$ lyophilized cell biomass was homogenized and soaked in $n$-hexane. The extraction process was repeated several times till the supernatant was colorless and then combined in a pre-weighed glass vial. The crude hydrocarbon extract was dried under gentle flow of nitrogen gas (>99\%).

The sample of the crude hydrocarbon was then purified by column chromatography on silica gel with $n$-hexane as an eluent. The residual extracts were fractionated on a same column using chloroform and methanol. As a result, pure hydrocarbon, non-polar lipids and polar lipids were well isolated with reference to their elution with that of the retention times of the internal standard (Largeau et al., 1980; Singh and Kumar, 1992; Dayananda et al., 2005). The composition of pure hydrocarbon was analyzed by GC-MS using Agilent HP-5 MS column (length $=30 \mathrm{~m}$, inner diameter $=0.25 \mathrm{~mm}$, film thickness $=0.25 \mu \mathrm{m}$ ) as described by Dayananda et al. (2005). The eluent of pure hydrocarbon from silica gel was firstly concentrated and then directly injected into the GC-MS machine for analyzing without derivatization.

\subsection{Carbohydrate and protein estimation}

The $B$. braunii cells which attached on the membrane were rinsed and re-suspended with de-ionized water and then freezedrying. A small amount of dry algal powder was added for carbohydrate and protein assay. Carbohydrates were quantified by the phenol-sulfuric acid colorimetric method of Hodge and Hofreiter (1962). Protein content was analyzed by Bradford protein assay according to Zor and Selinger (1996).

\subsection{Cobalt and nitrogen quantity determination in Chu 13 culture medium}

The concentration of cobalt in the culture medium was determined by ion chromatography (ICS-5000, Dionex, American) equipped with a conductivity detector (Dionex). Samples were injected with volume of $25 \mu \mathrm{l}$ by an autosampler unit. The stationary phase was an Ion Pac cs12A column (Dionex). The elution buffer consisted of $5 \mathrm{mM}$ methanesulfonic acid (Wang et al., 1984). The concentrations of nitrate in media were measured by the method of Collos et al. (1999). An aliquot of $2 \mathrm{ml}$ culture medium was centrifuged at $10,000 \times \mathrm{g}$ for $5 \mathrm{~min}$ and the supernatant was then collected. The optical density of the supernatant at $220 \mathrm{~nm}$ 
was measured, and the mole concentration of nitrate $(C, \mathrm{mM})$ calculated according to the standard curve.

$C=0.28290 D_{220}-0.0388\left(r^{2}>0.99\right)$

where $C$ is the nitrogen concentration ( $\mathrm{mM})$.

\section{Results and discussion}

\subsection{Effect of cobalt on B. braunii growth with attached cultivation}

As shown in Fig. 1a, the concentration of cobalt in the range of $0.09-4.50 \mathrm{mg} \mathrm{L}^{-1}$ can well support the growth of $B$. braunii with attached cultivation under the investigated conditions. The biomass productivity of $B$. braunii in a culture period of day 8 was $6.8,6.6,6.4$ and $6.6 \mathrm{gm}^{-2} \mathrm{~d}^{-1}$, respectively, corresponding to the cobalt concentration of $0.09,0.18,0.45$ and $0.90 \mathrm{mg} \mathrm{L}^{-1}$, respectively (Fig. 1b), without any significant differences. In the first 4 days of cultivation, the biomass productivity of $50 \times$ cobalt (4.5 $\mathrm{mg} \mathrm{L}^{-1}$ ) treatment was non-significantly different with lower cobalt treatments, however, at day 8 , it was $5.4 \mathrm{gm}^{-2} \mathrm{~d}^{-1}$, which is significantly lower. The growth of algal cells was highly restrained at extreme high cobalt treatment of $500 \times\left(45 \mathrm{mg} \mathrm{L}^{-1}\right)$, under which the biomass productivity was only $0.98 \mathrm{gm}^{-2} \mathrm{~d}^{-1}$ (Fig. 2b). According to these results, the cobalt concentration of $0.09 \mathrm{mg} \mathrm{L}^{-1}$ and $4.50 \mathrm{mg} \mathrm{L}^{-1}$ were selected as control and cobalt enrichment treatment, respectively.

The cobalt concentrations decreased sharply in 2 days for the enrichment treatment. The reduction rate greatly decreased in the following days. By the end of experiment, some residual cobalt (0.71 $\mathrm{mg} \mathrm{L}^{-1}$ ) was still detected (Fig. 2a). This result indicated high
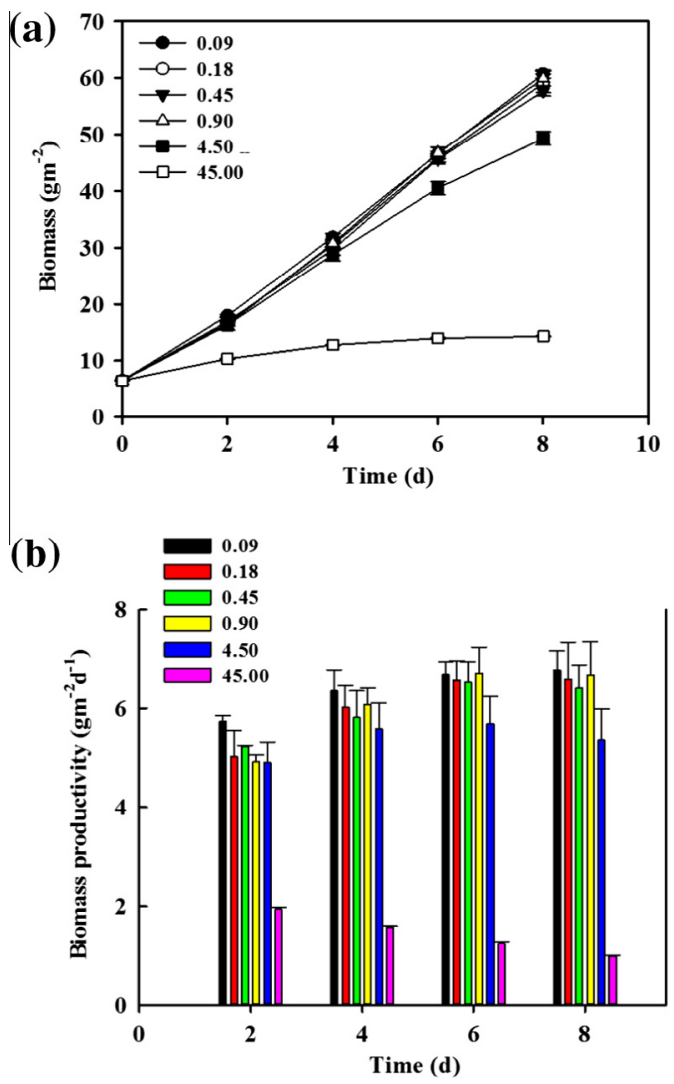

Fig. 1. Effects of cobalt concentration on growth and biomass productivity of $B$. braunii with biofilm attached cultivation. Results were average \pm standard derivation of 9 replications ( 3 measurements for each of 3 independent experiments). The figures beside the legend represented the Co concentrations ( $\left.\mathrm{mg} \mathrm{L}^{-1}\right)$.
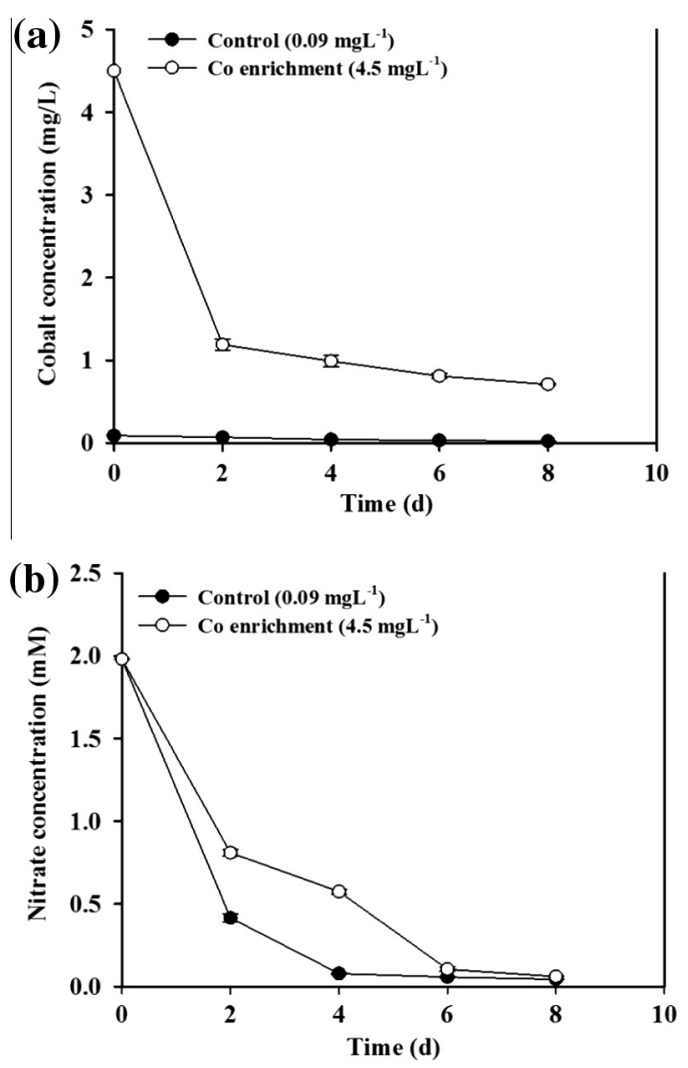

Fig. 2. Effects of cobalt enrichment on cobalt and nitrate concentrations of cultivation broth of $B$. braunii with biofilm attached cultivation. Results were average \pm standard derivation of 9 replications ( 3 measurements for each of 3 independent experiments).

potential of cobalt removal with the attached cultivation of B. braunii. In this study, ca. $85 \%$ of the total cobalt were removed from aqua solution to algal biomass and the cobalt binding capacity of B. braunii with attached cultivation was $1473.9 \mu \mathrm{mol} \mathrm{g}^{-1}$, which were apparently higher than the $560 \mu \mathrm{mol} \mathrm{g}^{-1}$ of Pilayella littoralis (Carrilho and Gilbert, 2000). Carrilho and Gilbert (2000) also revealed that biosorption of algae was rapid and accumulation of metals happened within short time, which was also demonstrated in our research (Fig. 2a). Fig. 2b clearly shows that nitrogen content with both of the normal and high cobalt concentration dropped continuously and in a steady fashion during culture time, from the same initial concentration of $1.98 \mathrm{mM}$ to nearly zero. However, nitrogen consumption with high cobalt was slower than the rate of control. Comparing Fig. 2a and b, nitrogen was almost exhausted after cobalt was consumed (cobalt enrichment). This was possible because the removal of cobalt seemed to be attributed to exchange of ions and high cobalt in the medium prevented nitrogen access to cell through ion channels on the biomembrane (Crist et al., 1994). The process of nitrogen consumption with normal cobalt in Chu 13 growth medium was compatible with other reports. Meanwhile, it was also obvious that cell growth continued after nitrogen was exhausted from the culture, which suggesting that intracellular nitrogen pools could be consumed to support cell growth (Li et al., 2008).

\subsection{Effect of cobalt enrichment on B. braunii hydrocarbon production with attached cultivation}

As shown in Fig. 3, cobalt enrichment treatment resulted in higher content of crude hydrocarbon compared to the control throughout the experiment. Moreover, crude hydrocarbon content 
(a)

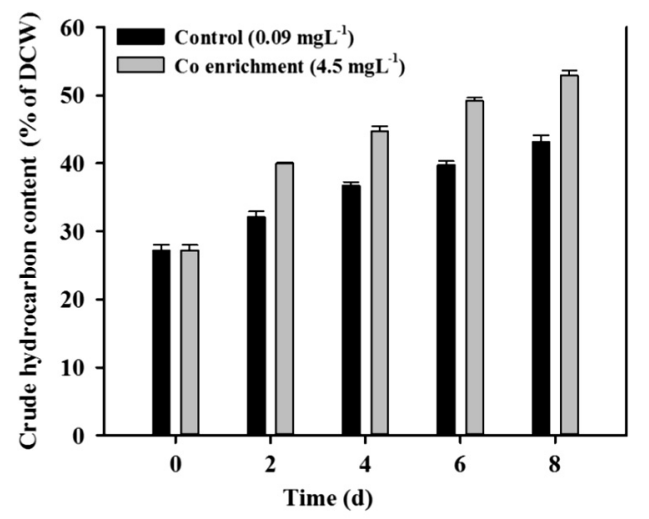

(b)

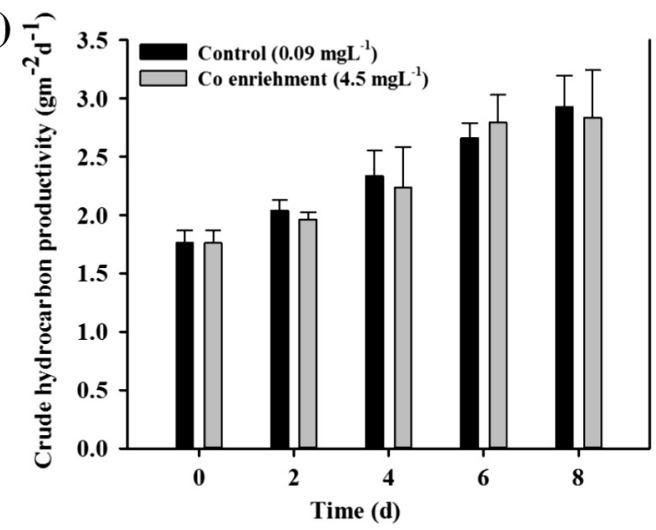

Fig. 3. Effects of cobalt enrichment on crude hydrocarbon content and productivity of $B$. braunii with biofilm attached cultivation. Results were average \pm standard derivation of 3 replications ( 1 measurement for each of 3 independent experiments).

increased with the culture time. On day 8 , the control reached a maximum crude hydrocarbon content of $43.2 \%$, while the Co enrichment samples reached a maximum of $52.9 \%$. Although the biomass productivity with high cobalt $\left(5.36 \mathrm{gm}^{-2} \mathrm{~d}^{-1}\right)$ was lower than the control $\left(6.8 \mathrm{gm}^{-2} \mathrm{~d}^{-1}\right)$, the crude hydrocarbon productivity was similar (2.8 and $2.9 \mathrm{gm}^{-2} \mathrm{~d}^{-1}$, respectively). Also, as showed in Table 1 that pure hydrocarbon content with Co enrichment $(29.7 \%)$ was higher than that of the control $(22.1 \%)$. The hydrocarbon produced from race $A B$. braunii usually contains the profile of $C_{25}-C_{31}$ numbered $n$-alkadienes and trienes. As shown in Fig. 4 , the content of long chain $C_{31}$ hydrocarbon with Co enrichment treatment was $24.9 \%$, much higher than that of control (15.3\%), meanwhile the content of $\mathrm{C}_{29}$ hydrocarbon was similar with both the employed cobalt concentrations. The content of $\mathrm{C}_{27}$ hydrocarbon with Co enrichment treatment was 13.9\%, which was lower than that of control (18.0\%).

Table 1

Effects of cobalt enrichment on components of crude hydrocarbon of B. braunii with biofilm attached cultivation.

\begin{tabular}{lll}
\hline $\begin{array}{l}\text { Components of crude } \\
\text { hydrocarbon }\end{array}$ & $\begin{array}{l}\text { Co enrichment } \\
\text { DCW }\end{array}$ & $\begin{array}{l}\text { Control }^{\mathrm{b}} \text { (\% } \\
\text { DCW })\end{array}$ \\
\hline Pure hydrocarbon & 29.7 & 22.1 \\
Non-polar lipids & 14.1 & 17.0 \\
Polar lipids & 7.9 & 3.1 \\
Chlorophyll and other impurity & 1.2 & 0.9
\end{tabular}

Results were mean of 3 replications ( 1 measurement for each of 3 independent experiments). Samples are attach-cultivated for 8 days.

a The Co concentration was $4.5 \mathrm{mg} \mathrm{L}^{-1}$.

b The Co concentration was $0.09 \mathrm{mg} \mathrm{L}^{-1}$.

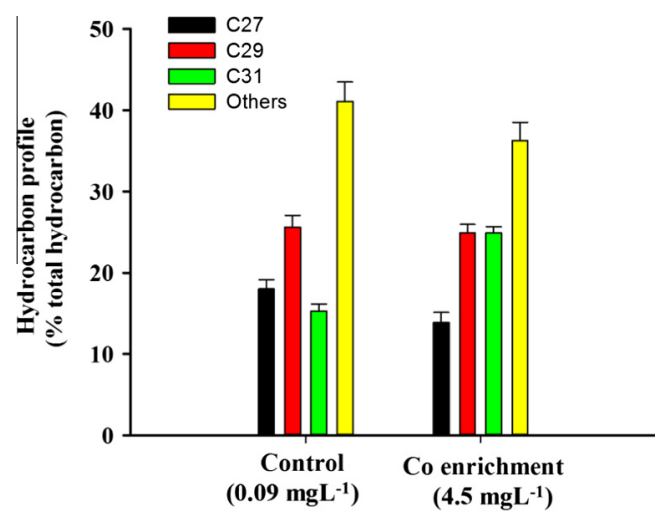

Fig. 4. Effects of cobalt enrichment on hydrocarbon profile of $B$. braunii with biofilm attached cultivation. Results were average \pm standard derivation of 3 replications ( 1 measurement for each of 3 independent experiments). Samples are attachcultivated for 8 days.

These results suggested that high cobalt concentrations would enhance the activity of the cobalt-porphyrin enzyme thus accelerating the synthesis of hydrocarbon (Dennis and Kolattukudy, 1992). Banerjee et al. (2002) reported that the synthesis of hydrocarbons in $B$. braunii is catalyzed by an elongation-decarboxylation mechanism, in which the oleic acid acting as a direct precursor and C2 units derived from malonyl Co-A is successively added until the appropriate chain lengths are attained. The final step of this synthesis route is decarbonylation, the loss of $\mathrm{CO}$ from fatty aldehyde to form hydrocarbon, which is catalyzed by the cobalt-porphyrin enzyme (Dennis and Kolattukudy, 1992).

\subsection{Effect of cobalt enrichment on B. braunii carbohydrate and protein production with attached cultivation}

The content of carbohydrate and protein on different days with Co enrichment treatment were shown in Fig. 5. The carbohydrate content of Co enrichment was lower than those obtained in the control. In both the observed tests (control and Co enrichment) carbohydrate content firstly increased during the first 4 days of cultivation, and then decreased. Carbohydrates are major energy resources that could be directly consumed by the algal cells. The change style of carbohydrates can be served as an indicative of how the organism adapted to the environment. As reported by Casadevall et al. (1985), B. braunii of A race can produce considerable amounts of carbohydrate. However, the amount of carbohydrate production varies with the strains, the race, physiological conditions as well as cultural conditions (Banerjee et al., 2002). In this research, $B$. braunii SAG 807-1 (A race) produced the largest carbohydrate content of biomass with normal cobalt was $16.4 \%$ and $14.1 \%$ with high cobalt at day 4 . The content of protein in control was higher than that of Co enrichment treatment, where the highest values were $6.2 \%$ and $4.2 \%$, respectively at day 4 . Changes in protein can reflect the rate of metabolic activity in actively growing cells (Chen and Vaidyanathan, 2013). Both of the contents carbohydrates and proteins were lower in Co enrichment treatment compared with control, meanwhile the hydrocarbon content was high. These results suggested that under Co enrichment conditions, the carbon resource inside the algal cells of B. braunii SAG 807-1 would like to flow from carbohydrates and proteins to hydrocarbon. It is also Noticeable that for both of the Co treatments, the content of carbohydrate as well as protein increased firstly and then decreased. This phenomenon might be also related with the carbon flow inside the cells. However the reason for this phenomenon might not be simply dedicated to the Co treatment 
(a)

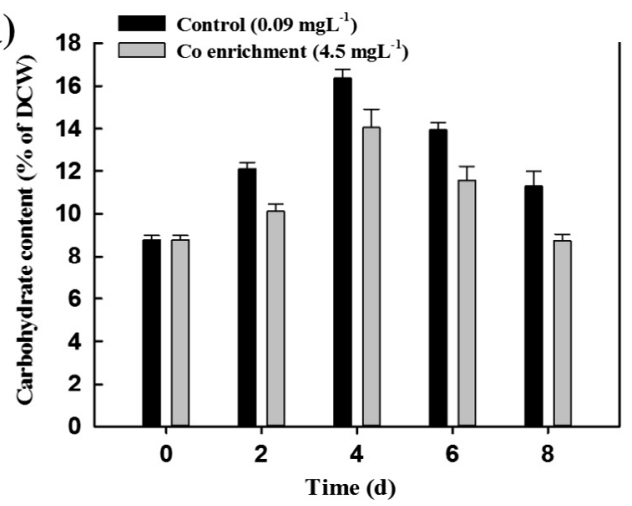

(b)

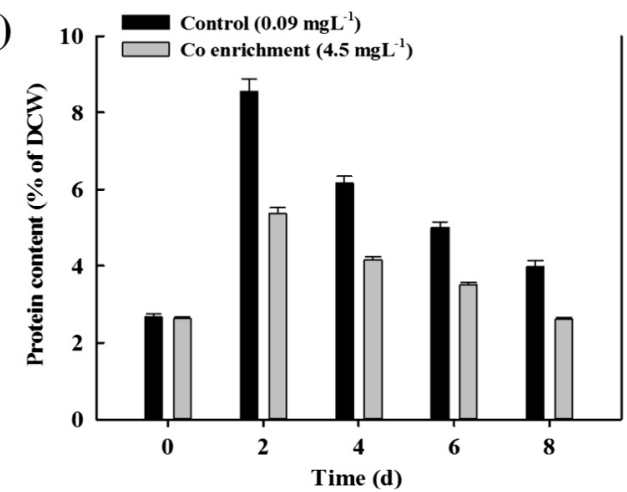

Fig. 5. Effects of cobalt enrichment on carbohydrate content and protein content of $B$. braunii with biofilm attached cultivation. Results were average \pm standard derivation of 3 replications ( 1 measurement for each of 3 independent experiments).

because the algal cells also experienced nitrogen starvation by the later phase of cultivation (Fig. 2b). Additional experiment with longer duration and without nitrogen starvation would certainly be of interest.

\section{Conclusions}

Under biofilm attached cultivation conditions, the microalga B. braunii survived high concentration of cobalt $(50 \times$ normal level). The crude hydrocarbon content as well as the long $C$ chain component were increased under Co enrichment treatment indicating the activity of key enzyme that catalyze hydrocarbon synthesis might be enhanced by Co enrichment. The reduced carbohydrate and protein contents accompanied by increased hydrocarbon content for Co enrichment treatment indicating the Co was also an effective factor that controls the carbon flow of B. braunii.

\section{Acknowledgements}

This work was supported by the National Natural Science Foundation of China (41276144), the Director Innovation Foundation of Qingdao Institute of Bioenergy and Bioprocess Technology, CAS and Science and Technology Development Planning of Shandong Province (2013GHY11520).

\section{References}

Baba, M., Kikuta, F., Suzuki, I., Watanabe, M.M., Shiraiwa, Y., 2012. Wavelength specificity of growth, photosynthesis, and hydrocarbon production in the oilproducing green alga Botryococcus braunii. Bioresour. Technol. 109, 266-270.

Banerjee, A., Sharma, R., Chisti, Y., Banerjee, U.C., 2002. Botryococcus braunii: a renewable source of hydrocarbons and other chemicals. Crit. Rev. Biotechnol. 22, 245-279.

Boyer, G.L., Brand, L.E., 1998. Trace elements and harmful algal blooms. In: Anderson, D.M., Cembella, A.D., Hallegraef, G.M. (Eds.), Physiological Ecology of Harmful Algal Blooms. Springer, Berlin, Germany, pp. 489-508.

Carrilho, E., Gilbert, T.R., 2000. Assessing metal sorption on the marine alga Pilayella littoralis. J. Environ. Monit. 2, 410-415.

Casadevall, E., Dif, D., Largeau, C., Gudin, C., Chamount, D., Desanti, O., 1985. Studies on batch and continuous culture of Botryococcus braunii: hydrocarbon production in relation to physiological state, cell ultrastructure and phosphate nutrition. Biotechnol. Bioeng. 27, 286-295.

Chen, Y., Vaidyanathan, S., 2013. Simultaneous assay of pigments, carbohydrates, proteins and lipids in microalgae. Anal. Chim. Acta 776, 31-40.

Cheng, P.F., Ji, B., Gao, L.L., Zhang, W., Wang, J.F., Liu, T.Z., 2013. The growth, lipid and hydrocarbon production of Botryococcus braunii with attached cultivation. Bioresour. Technol. 138, 95-100.

Cheng, P.F., Wang, J.F., Liu, T.Z., 2014. Effects of nitrogen source and nitrogen supply model on the growth and hydrocarbon accumulation of immobilized biofilm cultivation of B. braunii. Bioresour. Technol. 166, 527-533.

Collos, Y., Mornet, F., Sciandra, A., Waser, N., Larson, A., Harrison, P.J., 1999. An optical method for the rapid measurement of micromolar concentrations of nitrate in marine phytoplankton cultures. J. Appl. Phycol. 11, 179-184.

Crist, R.H., Martin, R., Carr, D., Watson, J.R., Clarke, H.J., Crist, D.R., 1994. Interaction of metals and protons with algae. 4. Ion exchange vs. adsorption models and reassessment of scatchard plots; ion-exchange rates and equilibria compared with calcium alginate. Environ. Sci. Technol. 28, 1859-1866.

Dayananda, C., Sarada, R., Bhattacharya, S., Ravishankar, G.A., 2005. Effect of media and culture conditions on growth and hydrocarbon production by Botryococcus braunii. Process Biochem. 40, 3125-3131.

Dennis, M., Kolattukudy, P.E., 1992. A cobalt-porphyrin enzyme converts a fatty aldehyde to a hydrocarbon and CO. PNAS 89, 5306-5310.

Hodge, J.E., Hofreiter, B.T., 1962. Determination of reducing sugars and carbohydrates. In: Whistler, R., Wolfrom, M. (Eds.), Methods Carbohydrate Chemistry. Academic Press, New York, pp. 380-394.

Ji, C., Wang, J., Zhang, W., Liu, J., Wang, H., Gao, L., Liu, T., 2014. An applicable nitrogen supply strategy for attached cultivation of Aucutodesmus obliquus. J. Appl. Phycol. 26, 173-180.

Koboyashi, M., Shimizu, S., 1999. Cobalt proteins. Eur. J. Biochem. 261, 1-9.

Largeau, C., Caradevall, E., Berkaloff, C., Dhamliencourt, P. 1980. Sites of accumulation and composition of hydrocarbons in Botryococcus braunii. Phytochemistry 19, 1043-1051.

Li, Y., Horsman, M., Wang, B., Wu, L., Lan, C., 2008. Effects of nitrogen sources on cell growth and lipid accumulation of green alga Neochloris oleoabundans. Appl. Microbiol. Biotechnol. 81, 629-636.

Liu, T., Wang, J., Hu, Q., Cheng, P., Ji, B., Liu, J., Chen, Y., Zhang, W., Chen, X., Chen, L. Gao, L., Ji, C., Wang, H., 2013. Attached cultivation technology of microalgae for cost-affordable biomass feedstock production. Bioresour. Technol. 127, 216222.

Metzger, P., Largeau, C., 2005. Botryococcus braunii: a rich source for hydrocarbons and related ether lipids. Appl. Microbiol. Biotechnol. 66, 486-496.

Rousch, J., Sommerfeld, M., 1999. Effect of manganese and nickel on growth of selected algae in pH buffered medium. Water Res. 33, 2448-2454.

Ruangsomboon, S., 2012. Effect of light, nutrient, cultivation time and salinity on lipid production of newly isolated strain of the green microalga, Botryococcus braunii KMITL 2. Bioresour. Technol. 109, 261-265.

Sawayama, S., Minowa, T., Dota, Y., Yokayama, S., 1992. Growth of hydrocarbon rich microalga Botryococcus braunii in secondarily treated sewage. Appl. Microbiol. Biotechnol. 38, 135-138.

Singh, Y., Kumar, H.D., 1992. Lipid and hydrocarbon production by Botryococcus spp. under nitrogen limitation and anaerobiosis. World J. Microbiol. Biotechnol. 8, $121-124$.

Wang, W., Chen, Y., Wu, M., 1984. Complementary analytical methods for cyanide, sulphide, certain transition metals and lanthanides in ion chromatography. Analyst 109, 281-286.

Weiss, T.L., Spencer, J., Fujisawa, K., Sumimoto, K., Okada, S., Chappell, J., Devarenne, T.P., 2010. Phylogenetic placement, genome size, and GC content of the liquidhydrocarbon-producing green microalga Botryococcus braunii strain Berkeley (Showa) (Chlorophyta). J. Phycol. 46, 534-540.

Zor, T., Selinger, Z., 1996. Linearization of the bradford protein assay increases its sensitivity: theoretical and experimental studies. Anal. Biochem. 236, 302-308. 